\title{
PRELIMINARY REPORT OF THE MAPPING OF THE BASALTS OF PARTS OF MILNE LAND AND GÅSELAND
}

\author{
W. Stuart Watt and Margrethe Watt
}

In the summer of 1970 field work on the Tertiary basalts was concentrated in the southern part of Milne Land and in the inner part of Gaseland based on three camps in each of these areas (fig. 8). The work was a direct continuation of the investigations from the two previous years (Watt, $1969 \& 1970$ ) and included part of the area already visited by Wenk (Wenk, 1961).

Due to a late start of the season only 13 sections were traversed distributed with 9 on Milne Land and 4 on Gåseland. From each camp one or more basalt sections were examined in detail and in addition a couple of rapid traverses were made during helicopter reconnaissance. Particular emphasis was placed on attempts to correlate the different basalt sections.

\section{General features}

The basalts overlie basement gneisses and towards the east on Milne Land they also overlie Mesozoic sediments. In the eastern part of the area there are valleys eroded in the pre-basalt peneplain up to $350-400 \mathrm{~m}$ in depth and with a general NWSE direction. In Tertiary time these valleys were filled with lava forming pools up to $60 \mathrm{~m}$ deep. The lava in these pools often shows regular columnar jointing. Outside the pools the thickness of the flows ranges from a couple of metres up to $50 \mathrm{~m}$, the average flow thickness varying from profile to profile. On southern Milne Land, where the basalt succession reaches a total of about $700 \mathrm{~m}$ consisting of approximately 30 flows, the average flow thickness varies from about $28 \mathrm{~m}$ in the south and thins to about $20 \mathrm{~m}$ to the north of "Vinkeldal". Thinning northwards is clearly seen in the characteristic $\beta$ flow. In NW Gåseland the basalt succession is about $450 \mathrm{~m}$ composed of about 20 flows with an average thickness of about $23 \mathrm{~m}$. Where a group of flow units were seen to belong to one volcanic event they were counted as one flow, but in practice this does not make much difference to the average flow thickness. 


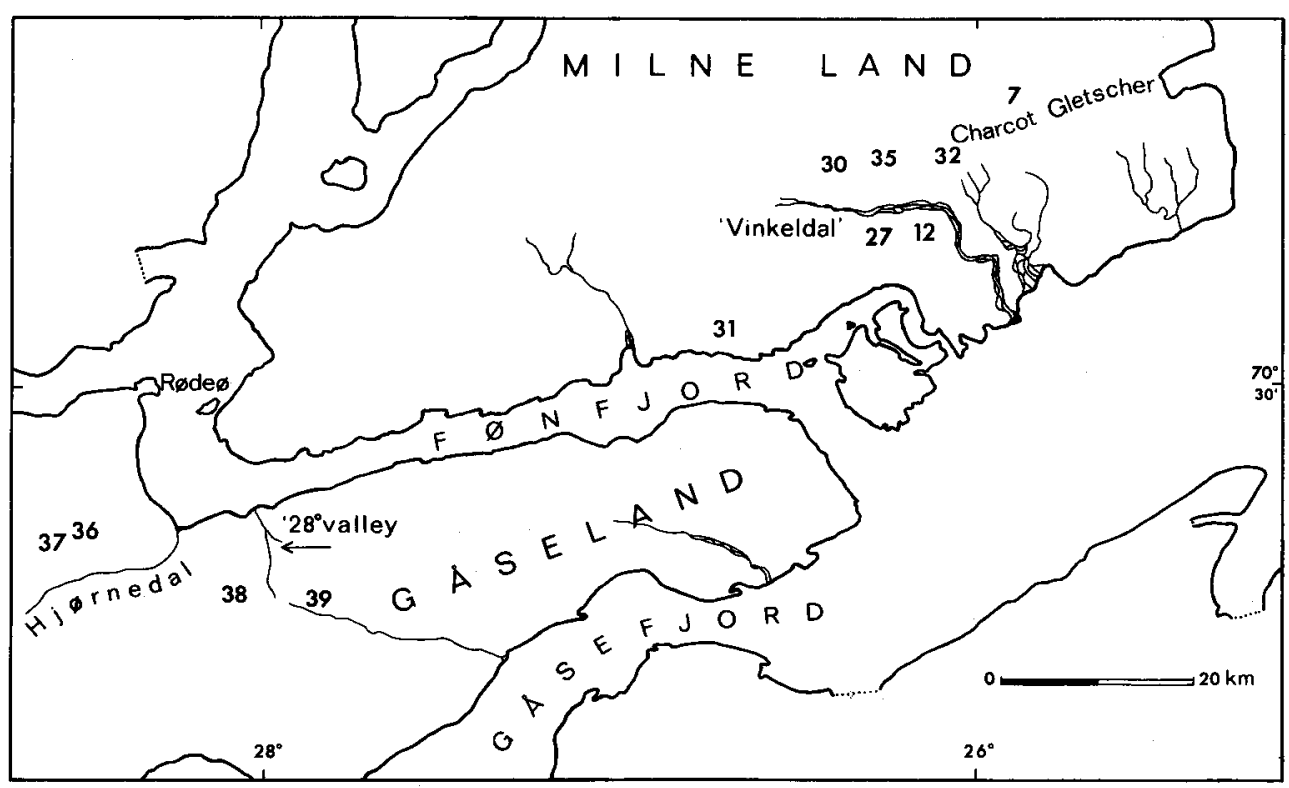

Fig. 8. Sketch map showing the distribution of the main basalt sections on Milne Land and Gåseland.

\section{Morphology of the flows}

Columnar jointing is common but regular hexagonal columns are rare except in very thick flows or lava basins where they occasionally form tiers of shorter columns. However, some thinner flows also seem to have a tendency to form more or less regular columns over a large part of their lateral extent - a fact which has been used for correlation purposes.

Characteristic weathering features seem to be fairly consistent throughout the lateral extent of a flow but normally change from base to top of the flow. The most common type of flow consists from the base upwards of a thin chilled zone, followed by a massive columnar horizon with a steep weathering slope comprising on average $30-50 \%$ of the total thickness of the flow, which grades upwards into a vesicular top with a gentler slope and often marked by a gradual change in weathering colour.

In certain groups of flows (such as group IV on Gåseland, see below) the upper part of the flow consists of a purplish brecciated zone cemented by zeolitic material. The top is always well defined against the overlying flow and often divided from it by a thin tuff while the lower limit is often uneven. The zeolitic material is frequently confined to irregular gaps between the angular blocks of lava which are of the same type as the more solid part of the flow. This type of lava flow may belong to the aa variety. The purple-red discolouration of the upper blocky part may originate from inmixing of tuffacious material at the time of the outpour as well as from later seepage. 


\section{Composition of the basalts}

The composition of the basalts appears to be fairly homogeneous, being fine to medium grained and rarely completely aphyric. Feldspar phenocrysts commonly appear as single crystals and in small clusters, occasionally star-shaped.

One characteristic flow at the base of the Milne Land lava pile contains a large number of star-shaped phenocrysts averaging $2-3 \mathrm{~cm}$ in diameter. Pyroxene phenocrysts are rare and always small (up to $1 \mathrm{~mm}$ ).

\section{Pillow lava and pyroclastic deposits}

While subaerial lava flows form the majority of the volcanic sequence occasional depressions with pillow lava were seen on both Milne Land and Gåseland. Pillowlike structures were observed at the base of a thick pyroclastic horizon on both sides of " $28^{\circ}$ valley" in the inner part of northern Gåseland. Haematite coatings were seen on pillows at a badly exposed locality in Hjørnedal.

Pyroclastic deposits occur at several localities on both Milne Land and Gåseland, but suffer the disadvantage of rapid disintegration and hence are easily overlooked in the scree. The thinner horizons can often only be seen in vertical or near vertical walls and are characterised by their distinctive yellow-brown weathering colour. The most extensive pyroclastic horizon occurs in " $28^{\circ}$ valley" in Gåseland where it reaches about $25 \mathrm{~m}$ in thickness near the Fønfjord coast. $10 \mathrm{~km}$ to the south the horizon is hardly traceable - broken up and ingulfed in the lowest parts of the overlying lava flow. Where well developed it consists of a hyaloclastic breccia with a large number of pillows and pillow fragments of all sizes up to $1.5 \mathrm{~m}$ in diameter, the larger ones resembling oversized cow-pats dipping away from the fjord. The pillows are of the same basalt type as the underlying pillow-like formation and also closely resemble a group of overlying thin toes or flow units. There are no sharp divisions between the different layers and the whole horizon probably belongs to one and the same volcanic event. A less extensive pyroclastic (hyaloclastic) deposit west of the lower part of "Vinkeldal" locally reaches a thickness of $70 \mathrm{~m}$.

Tuff horizons are fairly common in the area normally appearing as $2-10 \mathrm{~cm}$ thick red sheets separating two flows. Only rarely do they reach a thickness of $1 \mathrm{~m}$ as was the case at the base of a section north of "Vinkeldal".

\section{Sandstones}

Arkosic sandstone horizons occur sporadically as thin inter-basaltic deposits rarely exceeding $0.5 \mathrm{~m}$ in thickness. They are most common in the lower part of the succession on Milne Land where they appear as local sheets or filling pockets in the under- 
lying flows. The sandstone is composed of angular or subangular quartz-feldspar grains with occasional basalt pebbles. In a pre-basalt valley in south Milne Land a number of successive lava flows can be seen filling the valley and bulging up at the edges against the basement gneisses. Here the flows in the valley are separated by thin wedges of sandstone derived from erosion of the nearby basement. The deposits are thickest near the edge of the former valley and thin rapidly away from the source rock.

In the same valley a couple of pieces of yellow sandstone 5-10 $\mathrm{m}$ across and about $2 \mathrm{~m}$ in thickness were seen engulfed in the top of the lowermost pool-forming flow. The sandstone is coarse with rounded pebbles up to $5-6 \mathrm{~cm}$ in diameter. No sandstone of this type is known to exist in the immediate neighbourhood, but patches of sandstone of similar type are exposed underlying basalt a couple of kilometres to the east and south-east, suggesting an easterly or south-easterly source for at least the lowest lava flow. No pre-basaltic sandstone is known to the west and north.

\section{Fossil vegetation horizons}

Traces of what is believed to be silicified "soil" are fairly common between flows in, for example; the south of Milne Land where pieces of silicified wood occur in the scree. A well-preserved silicified tree-stump with a diameter of about $40 \mathrm{~cm}$ was seen standing in what must be near its original position and several others could be traced at the same niveau, indicating a time gap after the outpour of the first flow in the region.

In a pre-basalt valley north-east of "Vinkeldal" several smaller trees had been engulfed by pillow lava. The wood was charred and all heat-cracks filled with zeolitic material giving the trunk a honeycomb structure.

\section{Correlation}

Particular attention was paid to correlation of the profiles, mainly by recognising single characteristic flows (e.g. $\beta$ and $\mu$ on Milne Land) or groups of flows (e.g. group IV on Gåseland) following these along their lateral extent. Factors taken into consideration were principally the general weathering features including colour, steepness of the weathering slope, tendency to form columns, proportions between the lower massive (colonnade) and upper blocky (entablature) parts of a flow, etc. Pyroclastic and sandstone horizons were only used for local correlation due to general bad exposure. Palaeomagnetic results (see below) were only used as checks in control sections and were deliberately not used for determination of boundaries between groups. 


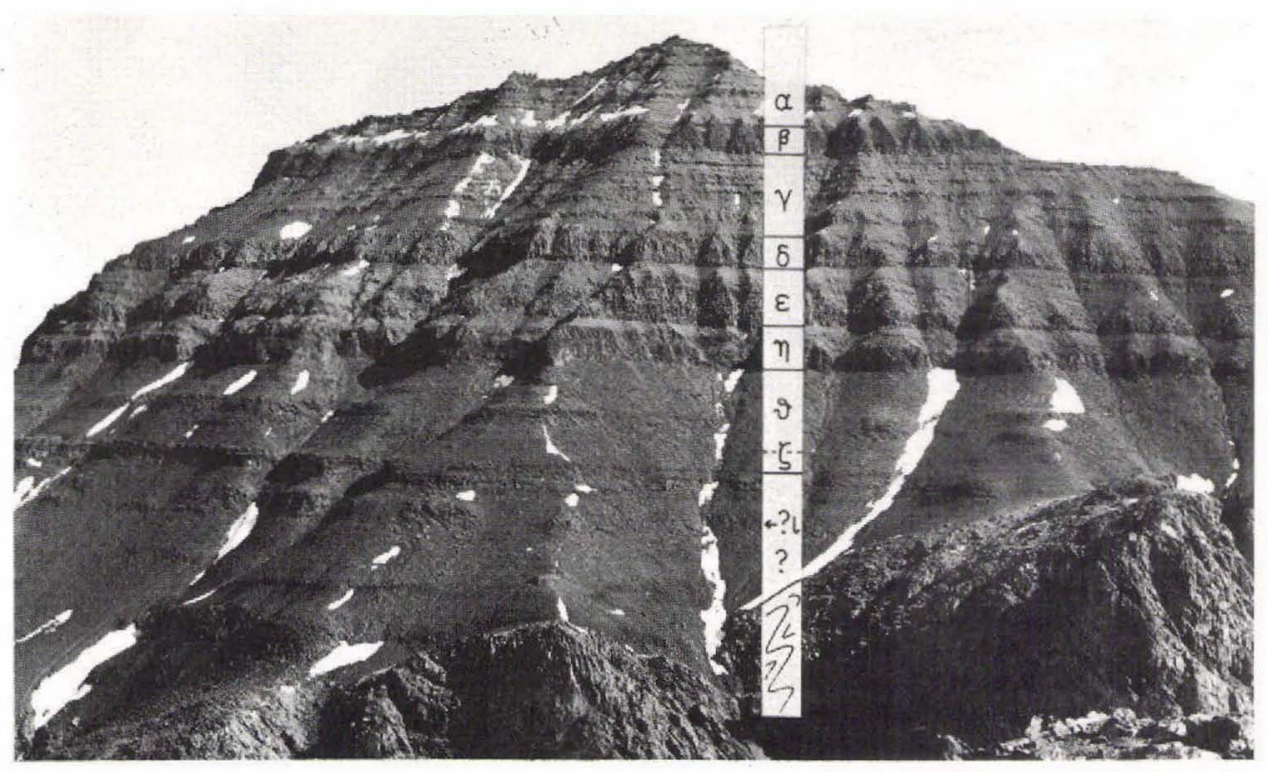

Fig. 9. Profile illustrating part of the Milne Land succession. The pyroclastic horizon $\zeta$ is indicated by its faster weathering leaving a bench on the top of the flow below. Scale: the height from the pyroclastic horizon bench to the base of the $\beta$ flow is $360 \mathrm{~m}$. Note also the pre-basaltic topography dropping into a valley to the left.

\section{Milne Land succession}

The Milne Land succession (fig. 9) consists from the top of:

$\omega$ : One to three prominent, grey to red-brown, cliff forming, thick, columnar flows. Only the lowest flow of the group has ever been examined, but in some places there are clearly three similar flows.

$\alpha$ : A group of grey weathering basalts with a very homogeneous appearance consisting of a number of flows or flow units. This group is underlain by

$\beta$ : one very prominent, red-brown weathering flow, often forming great, massive columns. The flow is fine-grained and almost non-porphyritic. Below this characteristic flow is

$\gamma$ : a zone of badly weathered basalt flows without marked features. This group is only distinguished by its position between $\beta$ and $\delta$.

$\delta$ : a prominent flow with normally well-developed, massive, yellow-brown columns at the top and bottom around a dark, blocky centre.

A pyroclastic horizon can sometimes be distinguished between $\gamma$ and $\delta$.

$\varepsilon, \eta \& \theta$ : zone of mostly badly exposed flows without characteristic features. $\eta$ is a dark flow overlying a pyroclastic horizon which is seen to separate $\eta$ from $\theta$ where exposure is sufficiently good.

६: A pyroclastic horizon below $\theta$.

$\iota$ : A prominent, massive flow with grey weathering colour, fine-grained with numerous, large, star-shaped phenocrysts - water-level agates occur in this flow.

$x$ : A zone of thinner, columnar flows with local sandstone and pyroclastic horizons.

$\lambda$ : A zone of badly weathered flows without marked features. $1 \mathrm{~cm}$ platy phenocrysts. A number of silicified tree-stumps were seen in situ in the fossil vegetation horizon between $\lambda$ and $\mu$.

$\mu$ : the lowest flow on Milne Land - pool-forming, massive, columnar, characterised by large $(3 \mathrm{~cm})$ star-shaped phenocrysts. 


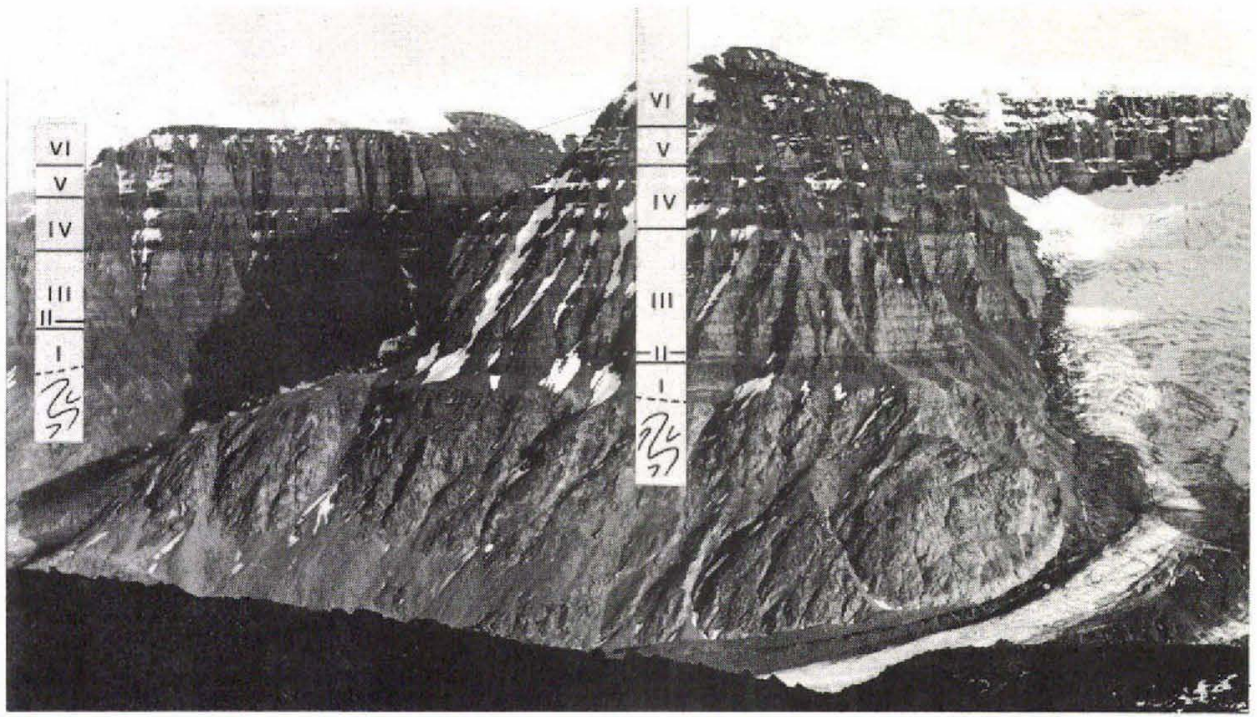

Fig. 10. Profile illustrating the Gàseland succession. Scale: the pyroclastic horizon (group II) to the base of group VI is about $360 \mathrm{~m}$.

The $\omega$ group of up to three flows is believed to form the uppermost flows in the Milne Land succession. Correlation was established across "Vinkeldal" and shows that no traceable tectonic movement has taken place along this marked topographic feature in post-basaltic time.

The scattered exposures north of Charcot Gletscher mapped in 1969 could not be linked on to the main profiles apart from the very extensive and characteristic $\mu$ flow which, judging from scattered outcrops $40 \mathrm{~km}$ to the east and north-east must have covered a very large part of the sandstone area of eastern Milne Land.

To the west and north basalt flows are banked up against the basement and the younger flows successively override more and more of the basement (cf. Wenk. 1961, fig. 16) indicating that the basalts were able to cover an increasing area of the gently, south-east sloping basement as the thickness of the basalt pile was built up. Later erosion has removed the main part of the basalts especially where they have overlain the Mesozoic sediments on south-eastern Milne Land. The western limit of the highest flows ( $\omega$ group) probably coincides with the limit of the basalt cover. The original south-eastern limit cannot be determined due to later erosion.

No correlation has yet been established across Fønfjord.

Gåseland succession

The basalts of NW Gåseland (fig. 10) were divided into six groups which described from the top are: 


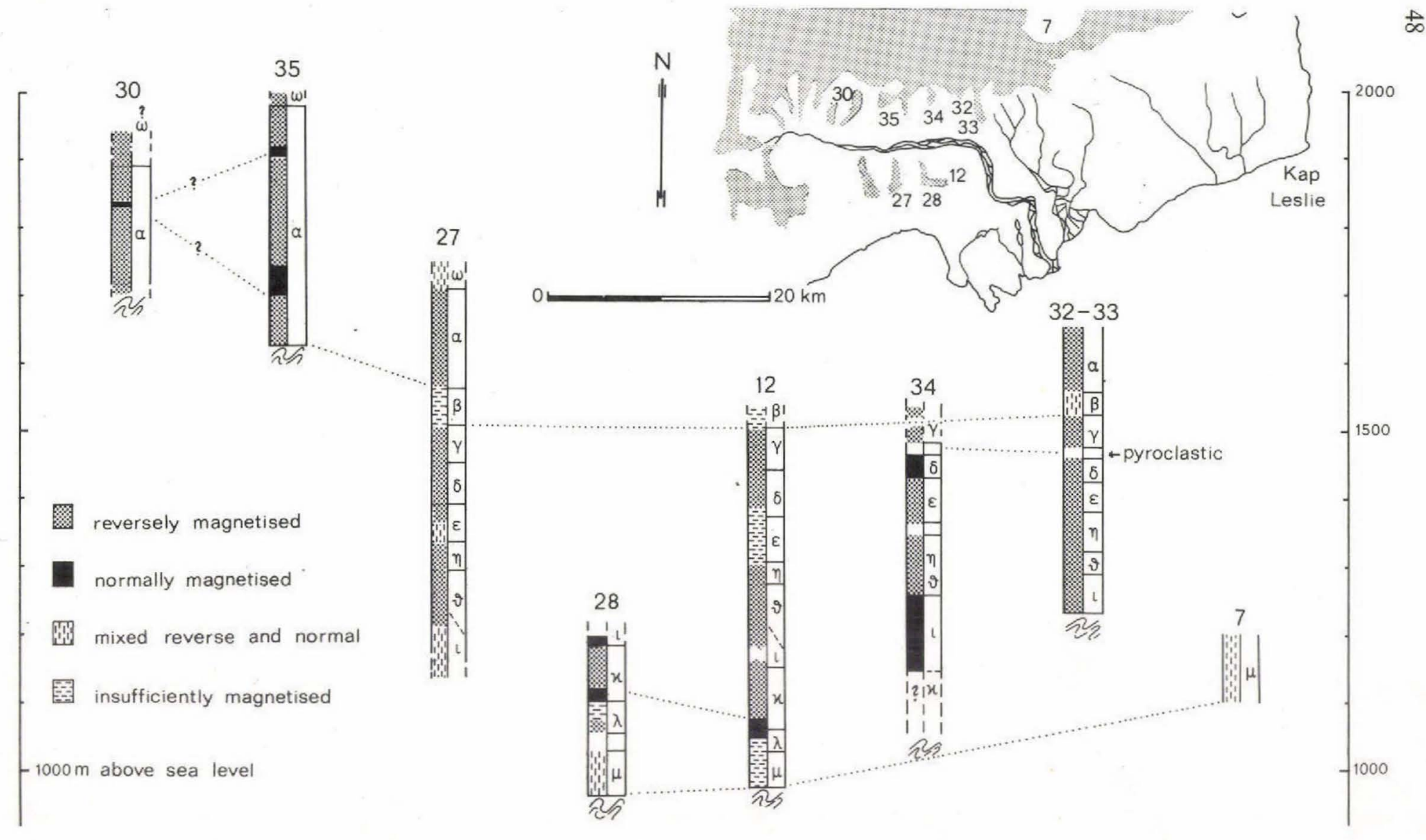

Fig. 11. Diagram showing the relationship between the remanent magnetisation and the field division of the basalt succession, and a possible correlation of the sections on south-east Milne Land. 
VI: Two or more prominent red-brown weathering flows with massive columns and thick purple tuff/breccia (?aa) at the top of each flow. This group is easily distinguished from $\mathrm{V}$.

V: A group of grey, fairly homogeneous flows or flow units, mostly medium grained with pahoehoe tops, particularly in the top part of the group. Towards the bottom the group becomes more mixed but is still grey in appearance. In most places it is easily distinguished from IV below.

IV: A very homogeneous group consisting of from 2 to 6 thick flows separated by tuff horizons. They are all fine grained. In one section (section 39) group IV is separated from $V$ by a prominent red-brown massive flow with a dark, blocky centre.

III: This group is less homogeneous than IV. It consists of a number of grey, occasionally grey-brown, flows or units. It is often badly exposed and is recognised mainly by its position between IV and II. In section 39 a dark, blocky flow forms a marker horizon between III and IV becoming more prominent in the direction of Gassefjord (to the south-east) and thinning to the north-west, but its lateral extent is unknown.

II : A pyroclastic horizon characterised by its yellow weathering colour.

I: Consists of the flows underlying the pyroclastic horizon (II). They are dark brown weathering flows the lower of which in places fills irregularities in the pre-basalt peneplain.

Groups III-VI can be traced laterally over the whole of the area examined, except perhaps north-west of Hjørnedal where the sections are too short for safe correlation over longer distances (sections 36 and 37). The general impression is, though, that these sections are of the same general appearance as the groups described above. Group II (pyroclastic horizon) is only present in the northern part of " $28^{\circ}$ valley", and $I$ is nearly always badly exposed banked against the rising basement along the Fønfjord coast.

\section{Dykes}

An east-west swarm of dykes in the Mesozoic sediments of eastern Milne Land continue with en échelon breaks westwards through the basalts on the northern side of "Vinkeldal" as a small dyke swarm. These dykes probably connect with the few NE-trending dykes that cut the gneisses on western Milne Land and the conglomerate on Rødeø to the west (Wenk, 1961). Most of the dykes cut completely through the lava pile; there being no indication that they are feeding channels to the lavas. The dykes are petrographically the same as the basalts in the area, and vary in width from half a metre to about $8 \mathrm{~m}$, the larger ones being multiple with signs of melting of adjacent wall rock. The en échelon breaks in the dykes are always to the right (dextral).

Around north-west Gåseland a few scattered dykes have a NE-SW direction and are always very thin. A few of these thin dykes were seen to peter-out upwards within the lava pile. 


\section{Palaeomagnetic field observations}

A crude survey of the remanent magnetism in the basalts was made with the use of a hand compass as a continuation of the work from 1969 (Watt, 1970) (for description af method see Abrahamsen, 1967 p. 372).

A total number of 399 readings were taken throughout the 13 sections described above distributed over 121 flows or groups of flows, giving an average of 3.3 readings per flow. The readings were taken avoiding the tops and bottoms of flows as occasional tests showed that the contact surfaces are liable to be affected by induced magnetisation.

A comparison between the field division of the basalt pile on Milne Land and the zones of reversely and normally magnetised flows is shown in fig. 11. It is emphasised that the field division was made independently of the direction of the magnetic polarity in the different horizons.

The diagram shows that the majority of the Milne Land lavas are reversely magnetised. Section 12 was traversed in 1969 but is shown for comparison. The diagram also shows that a change in magnetic characteristics in a number of places coincides with the boundary between two flow groups and that there is a fairly good agreement between the magnetic characteristics within the same flow or flow group.

Only two of the four sections in north-west Gåseland are sufficiently long to give material for a reliable magnetic comparison. The two sections are about $10 \mathrm{~km}$ apart and both comprise all six of the Gåseland flow groups, though group VI was never reached in one of them. Groups I, III and V show a very constant reverse magnetisation while group IV, consisting of four very characteristic (?) aa flows, gave equally consistantly mixed reverse and normal readings in both sections. This is considered to be of great interest as it shows that this palaeomagnetic field method at times can give extra support to a field division.

\section{References}

Abrahamsen, N. 1967: Some paleomagnetic investigations in the Faroe Islands. Meddr dansk geol. Foren. 17, 371-384.

Watt, W. S. 1969: The Tertiary basalts of Scoresby Sund, a preliminary report. Rapp. Gronlands geol. Unders. 21. 36-40.

Watt, W. S. 1970: Preliminary report of the mapping of the basalt area, south Scoresby Sund. Rapp. Gronlands geol. Unders. 30, 30-37.

Wenk, E. 1961 : On the crystalline basement and the basal part of the pre-Cambrian Eleonore Bay group in the southwestern part of Scoresby Sund. Meddr Gronland 168, 1. 